\title{
Synovial Chondromatosis of the Elbow Joint in a 27-Year-Old Man: A Case Report
}

\author{
Fatih Türkmensoy ${ }^{1}$, İsmail Türkmen ${ }^{1}$, Mehmet Salih Söylemez ${ }^{1}$, Yalçın Turhan ${ }^{2}$, \\ Birol Aktaş ${ }^{1}$, Feyza Ünlü Özkan ${ }^{3}$ \\ ${ }^{1}$ Department of Orthopaedics and Traumatology, Göztepe Training and Research Hospital, İstanbul Medeniyet University, İstanbul, \\ Turkey; ${ }^{2}$ Department of Orthopaedics and Traumatology, Düzce State Hospital, Düzce, Turkey; ${ }^{3}$ Department of Physical Therapy \\ and Rehabilitation, Fatih Sultan Mehmet Training and Research Hospital, İstanbul, Turkey. \\ Email: slhsylmz@gmail.com
}

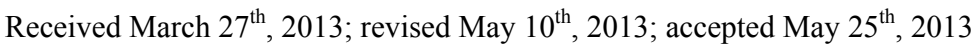

Copyright (C) 2013 Fatih Türkmensoy et al. This is an open access article distributed under the Creative Commons Attribution License, which permits unrestricted use, distribution, and reproduction in any medium, provided the original work is properly cited.

\begin{abstract}
Introduction: Multiple intraarticular loose bodies are pathognomonic for the Synovial chondromatosis. This disorder affects a wide age range from adults to childhood with no sex dominance. Malignant transformation is rare to date, and there are approximately 34 cases in literature about the transformation of synovial chondromatosis to chondrosarcoma. Case: We present case of a 27-year-old patient who had synovial chondromatosis in his elbow. Discussion: Radiographic findings are usually pathognomonic for the diagnosis. Multiple calcified loose bodies can be seen in the joint in radiographs. Computed tomography (CT) optimally depicts the calcified intraarticular fragments and extrinsic bone erosion. However, because the radioopacity cannot be detected in $1 / 3$ of the cases, diagnosis becomes difficult. Treatment modalities include arthroscopic or open extraction of the loose bodies and arthropasty in the presence of severe osteoarthritis. Conclusion: Synovial chondromatosis should be kept in the differential dignosis of the chronic monoarticular pain and painful limitations of the range of motions of the joints.
\end{abstract}

Keywords: Elbow; Loose Body; Malignant Transformation; Synovial Chondromatosis; Treatment

\section{Introduction}

The term synovial chondromatosis describes idiopaticmetaplastic hyalin cartilage which expands to subsynovial connective tissue in a joint, tendon sheath, or bursa [1-3]. Multiple intraarticular loose bodies are pathognomonic for the disease. This disorder affects a wide age range from adults to childhood with no sex dominance $[1,2]$. Malignant transformation is rare, to date, there is aproximately 34 cases in literature about transformation of synovial chondromatosis to chondrosarcoma [2].

There are two forms of the disease. Primary synovial chondromatosis is a benign condition and characterized with multiple intraarticular bodies with chondroid metaplasia in the synovium. Joint effusion, crepitus and loss of range of motion of the joint can be seen. Secondary synovial chondromatosis is usually associated with trauma, degenerative joint disease, inflammatory arthropathies and neurological diseases, abnormalities which are the cause of chondral loose bodies and joint abnormalities $[1,3]$.
Usually it occurs in the large joints of the body such as hip and knee. The elbow is the very rare site for the disease and this location was firstly reported by Henderson M.S. in 1918 [4]. Clinical symptoms include pain, swelling and decrease in the range of motion, locking, articular crepitus and instability [3,5].

\section{Case Presentation}

27 year-old man presented with limitation in motion and progressively worsening right elbow pain with associated swelling. The pain was present when the patient was at rest, and worsened when the elbow in action. He did not describe any swelling and pain, limitating his job (patient is a body worker). The pain was started nine-years ago with fell down of a 50 kilograms block on his elbow. After the accident he examined at emergency service and radiological imaging was performed. There were no abnormalities determined in his elbow. Valgus and varus stres tests were negative. For pain and swelling elevation and cold-pad applied and he discharged with some medi- 

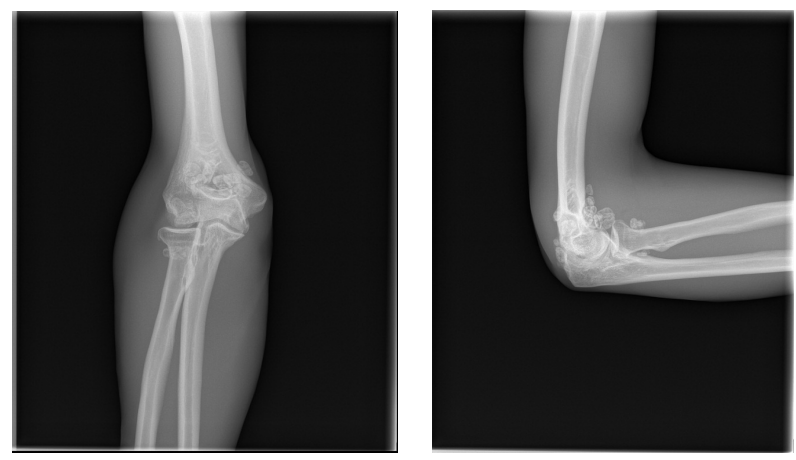

Figure 1. Preop X-ray of the right elbow.
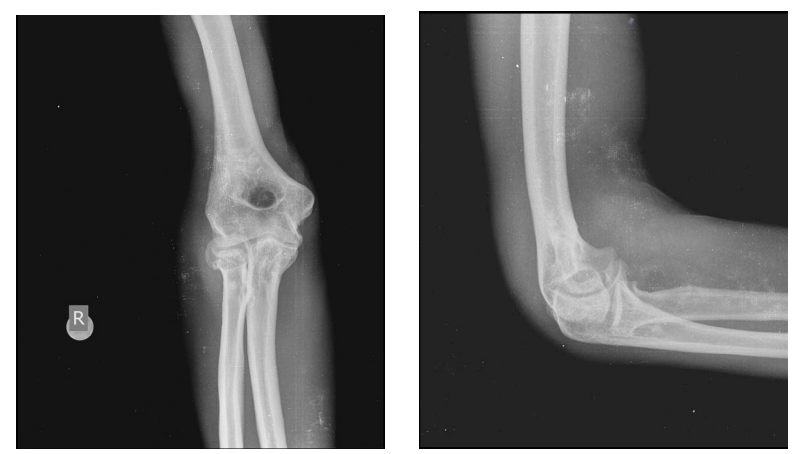

Figure 2. Postop X-rays of right elbow.

cine. A few weeks later his pain was decreased but never finished. After the trauma, his pain is increased slowly year by year and flexion limitation was added.

His elbow flexion was $90^{\circ}$, extansion was unlimited. He couldn't bring his hand to mouth. The pain wasn't increase with flexion-extantion or rotation.

Swelling wasn't detected on the examination. X-rays performed on his elbow. Elbow lateral and the A-P radiographics showed numerous chondromatic calsifications (Figure 1).

Under the general anaesthesia, an anterolateral incision was made. Joint capsule was reached through the interval between the anconeous and extansor carpi ulnaris muscles. Capsule was opened and 25 chondromatous lesions were exracted along the skin incision. The joint was irrigated and a partial synoviectomy was performed. Histopathology was consistent with synovial chonromatosis.

Postoperative control X-rays performed (Figure 2). The patient was stated on a gentle range of motion exercises and he had an elbow flexion of $120^{\circ}$ and $60-60$ pronation-supination at his last control, 3 months postoperatively.

\section{Discussion}

Synovial chondromatosis should be kept in the differantial diagnosis of painful limitation of range of motion of the joints. The symptoms and signs are not specific, hence, several differantial diagnosis should be kept in mind [6].
Especially, Physical Theraphy and Rehabilitation, Orthopaedics and Rheumatology doctors should suspect synovial originated chondromatosis as the possible source of symptoms related with joint like pain, effusion and locking [3].

Radiographic findings are usually pathognomonic for the diagnosis. Multiple calcified loose bodies can be seen in the joint in radiographs. Computed tomography (CT) optimally depicts the calcified intraarticular fragments and extrinsic bone erosion. However, because the radioopacity cannot be detected in $1 / 3$ of the cases diagnosis become difficult [3]. In these cases magnetic resonance imaging is an impaortant modality in diagnosis. Magnetic resonance (MR) imaging findings are more variable, depending on the degree of mineralization, although the most common pattern (77\% of cases) reveals low to intermediate signal intensity with $\mathrm{T} 1$ : weighting and very high signal intensity with $\mathrm{T} 2$ : weighting with hypointense calcifications [3].

Milgram has reported that multiple loose bodies can be found without any synovial metaplasia and divide the disease into three separate phases; stage 1 is synovial chondromatoplasia but no loose bodies, stage 2 is the active synovial disease and loose bodies, stage 3 is the late stage with loose bodies but no synovial disease [7]. Our patient's lesions were corresponding to stage two of Milgram. It may occasionally regress in spite of its progressive charecter and although it is very rare, malignant transformation of synovial chondromatosis can occur [8]. It should be suspected in chronic cases where acute exacerbation of symptoms of pain and swelling occur.

Treatment modalities include arthroscopic or open extraction of the loose bodies and arthropasty in the presence of severe osteoarthritis $[9,10]$.

In conclusion, synovial chondromatosis should be kept in the differential dignosis of the chronic monoarticular pain and painful limitations of the range of motions of the joints.

\section{REFERENCES}

[1] J. X. O'Connell, "Pathology of the Synovium," American Journal of Clinical Pathology, Vol. 14, No. 5, 2000, pp. 773-784. doi:10.1309/LWW3-5XK0-FKG9-HDRK

[2] B. L. Sperlıng, S. Angel, G. Stoneham, V. Chow, A. Mcfadden and R. Chibbar, "Synovial Chondromatosis and Chondrosarcoma: A Diagnostic Dilemma," Sarcoma, Vol. 7, No. 2, 2003, pp. 69-73.

[3] M. D. Murphey, J. A. Vidal, J. C. Fanburg-Smith and D. A. Gajewski, "Imaging of Synovial Chondromatosis with Radiologic-Pathologic Correlation," Raiographics, Vol. 27, No. 5, 2007, pp. 1465-1486. doi: $10.1148 /$ rg. 275075116

[4] M. S. Henderson, "Loose Bodies in the Elbow Joint," 
JAMA, Vol. 71, No. 3, 1918, pp. 177-180.

[5] N. Elmal1, İ. Esenkaya and A. Alkan, "Synovial Chondromatosis: A Report of Four Cases with Three Diverse Localizations," Acta Orthopaedica et Traumatologica Turcica, Vol. 37, No. 2, 2003, pp. 173-177.

[6] J. H. Christensen and J. O. Poulsen, "Synovial Chondromatosis," Acta Orthopaedica Scandinavica, Vol. 46, No. 6, 1975, pp. 919-925. doi:10.3109/17453677508989279

[7] J. W. Milgram, "Synovial Osteochondromatosis: A Histopathological Study of Thirty Cases," The Journal of Bone \& Joint Surgery, Vol. 59, No. 6, 1977, pp. 792-801.
[8] P. I.Wuisman, R. J. Noorda and P. C. Jutte, "Chondrosarcoma Secondary to Synovial Chondromatosis. Report of Two Cases and a Review of the Literature," Archives of Orthopaedic and Trauma Surgery, Vol. 116, No. 5, 1997, pp. 307-311. doi:10.1007/BF00390060

[9] S. Adıyaman, M. Demirtaş and Y. Sağlık, "Sinoviyal Kondromatozis," Artroplasti Artroskopik Cerrahi, Vol. 8, No. 1, 1994, pp. 55-56.

[10] T. Shpitzer, A. Ganel and S. Engelberg, "Surgery for Synovial Chondromatosis. 26 Cases Followed up for 6 Years," Acta Orthopaedica Scandinavica, Vol. 61, No. 6, 1990, pp. 567-569. doi:10.3109/17453679008993585 